\title{
AT-527 is a potent in vitro replication inhibitor of SARS-CoV-2, the virus responsible for the COVID-19 pandemic
}

Steven S. Good ${ }^{1 *}$, Jonna Westover ${ }^{2}$, Kie Hoon Jung ${ }^{2}$, Paolo La Colla ${ }^{3}$, Gabriella Collu ${ }^{3}$, Adel Moussa ${ }^{1}$, Bruno Canard ${ }^{4}$ and Jean-Pierre Sommadossi ${ }^{1}$

\author{
${ }^{1}$ Atea Pharmaceuticals, Inc., 125 Summer St., Suite 1675, Boston, MA 02110 USA \\ ${ }^{2}$ Institute for Antiviral Research, Utah State University, Logan, Utah 84322 USA \\ ${ }^{3}$ Università degli Studi di Cagliari 09042 Monserrato, Italy \\ ${ }^{4}$ Architecture et Fonction des Macromolécules Biologiques - CNRS UMR 725713009 Marseille, \\ France \\ *Corresponding Author: Steven S. Good good.steven@ateapharma.com
}

\begin{abstract}
AT-527, an orally administered double prodrug of a guanosine nucleotide analog, has been shown previously to be highly efficacious and well tolerated in HCV-infected subjects. Herein we report the potent in vitro activity of AT-511, the free base form of AT-527, against several coronaviruses, including SARS-CoV-2, the causative agent of COVID-19. In normal human airway epithelial (HAE) cell preparations, the average concentration of AT-511 required to inhibit replication of SARSCoV-2 by $90 \%$ (EC90) was $0.5 \mu \mathrm{M}$, very similar to the $\mathrm{EC}_{90}$ for AT-511 against HCoV-229E, HCoVOC43 and SARS-CoV in Huh-7 cells. No cytotoxicity was observed for AT-511 in any of the antiviral assays up to the highest concentration tested $(100 \mu \mathrm{M})$. Surprisingly, AT-511 was 30-fold less active against MERS-CoV. This differential activity may provide a clue to the apparent unique mechanism of action of the guanosine triphosphate analog formed from AT-527.
\end{abstract}

Keywords: AT-527, AT-511, COVID-19, SARS-CoV-2, coronavirus, antivirals

\section{INTRODUCTION}

A novel coronavirus, severe acute respiratory syndrome coronavirus-2 (SARS-CoV-2), was recently identified as the pathogen that causes the potentially life-threatening disease called coronavirus disease 2019 (COVID-19), which has rapidly spread across the world. Currently there are no vaccines or therapeutics approved to prevent SARS-CoV-2 infection or to treat COVID-19.

Recently remdesivir, the prodrug of an adenosine nucleotide analog, originally developed for the treatment of Ebola virus infections, has demonstrated potent in vitro activity against SARS-CoV2 (Wang et al., 2020) and has shown sufficient promise in the treatment of COVID-19 patients (Beigel et al., 2020) such that the FDA has granted Emergency Use Authorization to this nucleotide prodrug. The limited oral bioavailability of remdesivir (Eastman et al., 2020), however, requires that it be administered via intravenous infusion, thus limiting its use to hospitalized patients. COVID-19 is an acute viral infection for which antiviral therapeutics will be most 
effective within the first stage of the infection when viral load is at its maximum, with rapid viral replication initially in nasal, throat and pulmonary cells (Mason, 2020). Only the availability of a potent, safe, oral antiviral administered to SARS-CoV-2 infected individuals in their early stage of disease will avert clinical illness and mitigate the COVID-19 pandemic.

AT-527, an oral double prodrug of a guanosine nucleotide analog, has demonstrated potent in vitro activity against clinical isolates of hepatitis $\mathrm{C}$ virus (HCV) by inhibiting the RNA-dependent RNA polymerase (RdRp) (Good et al., 2020). Supported by a comprehensive preclinical toxicology and safety pharmacology package, AT-527 has recently been evaluated in a Phase 1B study (Berliba et al., 2019) and a Phase 2 clinical trial (Mungar, et al. 2020). In the latter study, AT-527 was safe and well-tolerated for up to 12 weeks in HCV-infected subjects and achieved a high rate of efficacy. Amid the SARS-CoV-2 pandemic, the activity of AT-511, the free base of AT-527, was tested in vitro against several human coronaviruses, including SARS-CoV-2.

\section{RESULTS}

In an initial screening, BHK-21 cells acutely infected with a seasonal human alpha coronavirus, HCoV-229E, were exposed to serial dilutions of AT-511. After a 3-day incubation, the effective concentration of AT-511 required to achieve $50 \%$ inhibition $\left(E C_{50}\right)$ of the virus-induced cytopathic effect (CPE) from two independent experiments averaged 1.8 $\mu \mathrm{M}$ (Table 1). In contrast, the 2'fluoro-2'-methyl uridine nucleotide prodrug sofosbuvir did not inhibit HCoV-229E replication at concentrations as high as $100 \mu \mathrm{M}$. No toxicity was detected from either drug.

The in vitro potency of AT-511 against HCoV-229E, HCoV-OC43 (another seasonal human coronavirus strain), MERS-CoV and SARS-CoV was then evaluated in Huh-7 cell-based assays. This human hepatocarcinoma cell line was selected based on its ability to activate AT-511 intracellularly to its triphosphate metabolite, unlike MRC-5 cells in which AT-511 lacked activity against HCoV-229E (EC $50>100 \mu \mathrm{M}$; Good et al., 2020). Antiviral activity was assessed by two different methods after exposure of Huh-7 cells to virus and serial dilutions of test compound by determining 1 ) the $\mathrm{EC}_{50}$ for virus-induced CPE by neutral red dye staining after a 5-day (229E and OC43) or 7-day (MERS and SARS) incubation and 2) the effective concentration required to reduce secretion of infectious virus into the culture medium by $90 \%$ (EC 90 ) after a 3-day incubation using a standard endpoint dilution $\mathrm{CCID}_{50}$ assay to determine virus yield reduction (VYR). Half-maximal cytotoxicity $\left(\mathrm{CC}_{50}\right)$ was measured by neutral red staining of compound-treated duplicates in the absence of virus. Although a robust VYR endpoint was obtained in Huh-7 cells infected with HCoVOC43 or SARS-CoV, CPE was not observed and EC $_{50}$ values using neutral red staining were not obtained with these viruses. Individual determinations of EC90 values for AT-511 against HCoV229E, HCoV-OC43 and SARS-CoV ranged from 0.34 to $1.2 \mu \mathrm{M}$, whereas the value against MERSCoV averaged $37 \mu \mathrm{M}$ (Table 1). No cytotoxicity was detected with AT-511 up to $86 \mu \mathrm{M}$, the highest concentration tested.

Chloroquine and hydroxychloroquine appeared to be quite potent against HCoV-229E and HCoVOC43 based on their $\mathrm{EC}_{90}$ values of $<0.05 \mu \mathrm{M}$ obtained using VYR measurements (Table 1). The respective $\mathrm{EC}_{50}$ values for these two drugs (8.1 and 7.4 $\mu \mathrm{M}$ ), obtained using the neutral red assay, were substantially higher and only 2.6 - to 3.6 -fold less than the corresponding $\mathrm{CC}_{50}$ values, 
indicating considerably lower potencies and poor selectivity indices. These differences illustrate an inherent error in assessing antiviral activities of cytotoxic compounds using only measurements of VYR. When cells are poisoned by toxic drugs and are progressing toward death, their ability to support viral replication and propagation in addition to their own health likely is greatly diminished. At the point when cell death is detected by staining, viral yield reduction measurements likely reflect a combination of antiviral activity and cytotoxicity, thus overestimating antiviral potencies.

In contrast to a recent publication (Wang et al., 2020), Huh-7 cells were not permissive for replication of SARS-CoV-2. An assay was developed using normal human airway epithelial (HAE) cells, a highly relevant in vitro model of the lung, which has been established as a more representative system than cell lines for SARS-CoV-2 replication (Jonsdottir and Dijkman, 2016). These primary cells form polarized monolayers, the apical side of which is exposed to air and produces a mucin layer, consistent with the physiology of the human airways (Sheahan et al., 2020). Average $E_{90}$ and $C_{50}$ values for AT-511 against SARS-CoV-2 from two separate HAE assays ( 0.5 and $>86 \mu \mathrm{M}$, respectively) were in the same range as those obtained for HCoV-OC43 and SARS-CoV (Table 1).

In the second HAE assay, the activity of AT-511 was tested in parallel with $\mathrm{N}^{4}$-hydroxycytidine (the nucleoside formed from the mutagenic oral prodrug EIDD-2801) with recently reported in vitro and in vivo activity against SARS-CoV-2 (Sheahan et al., 2020). The potency of $\mathrm{N}^{4}$ hydroxycytidine against SARS-CoV-2 $\left(\mathrm{EC}_{90}=3.9 \mu \mathrm{M}\right)$ was 8 times less than that of AT-511 in the same experiment.

\section{DISCUSSION}

The 30-fold difference of AT-511 activity between MERS-CoV and other CoVs is puzzling.

Nucleotide and nucleotide analogue selection is achieved at the CoV RdRp active site, the nsp12 gene product activated by its processivity co-factors nsp7 and nsp8 (Subissi et al., 2014).

Conserved amino acid motifs $A$ and $C$ are involved in phosphodiester bond formation, whereas motifs $F$ and $B$ participate in nucleotide channeling and binding at the active site, respectively. No significant structural differences are apparent between MERS-CoV and other CoVs in these essential motifs. With a similar ribose modification between AT-511 and sofosbuvir, it is unlikely that the selective lack of activity of sofosbuvir would be due to excision by the CoV exonuclease carried by nsp14 (Ferron et al., 2018). Rather, our results suggest that the triphosphate formed from AT-511 most likely targets another less conserved viral GTP-binding protein, whose inhibition would account for both the antiviral effect and the MERS-CoV differential sensitivity pattern.

To date, human safety and tolerability have been confirmed in more than $40 \mathrm{HCV}$-infected patients treated orally with once-daily administration of $550 \mathrm{mg}$ of AT-527 for seven days and up to 12 weeks. Excellent pharmacokinetics (50-60\% bioavailability and long intracellular half-life of the active metabolite) associated with a dosing regimen of a 1,100 mg loading dose, followed by $550 \mathrm{mg} \mathrm{BID}$, should provide lung drug exposures consistently above its in vitro $\mathrm{EC}_{90}$ of $0.5 \mu \mathrm{M}$ 
against SARS-CoV-2 replication and should lead to a very effective antiviral treatment. A Phase 2 clinical trial is currently ongoing to evaluate the safety and efficacy of AT-527 in COVID-19 patients. Additionally, the differential activities AT-511 against MERS-CoV in comparison to the other CoVs tested and of AT-511 in comparison to sofosbuvir against HCoV-229E are being exploited to probe the unique mechanism of inhibition of the active guanosine triphosphate analog formed from AT-527.

\section{DECLARATION OF INTERESTS}

The authors affiliated with Atea Pharmaceuticals, Inc. are employees of the company and own company stock. The other authors have no conflict of interest to report.

\section{AUTHOR CONTRIBUTIONS}

J.W. and K.J. developed and conducted the assays for HCoV-229E, HCoV-OC34, MERS-CoV and SARS-CoV-1 in Huh-7 cells and SARS-CoV-2 in HAE cell preparations. P.L.C. and G.C. developed and conducted the assays for HCoV-229E in BHK-21 cells. A.M. acquired the antivirals. S.G., A.M and J.S. designed the experiments. S.G., B.C. and J.S. wrote the manuscript. All authors provided input and final approval of the manuscript. 


\section{Table 1. In Vitro Activity of AT-511 and Other Oral Antiviral Drugs Against Various Human Coronaviruses}

\begin{tabular}{|c|c|c|c|c|c|c|}
\hline \multirow{2}{*}{$\begin{array}{l}\text { Virus } \\
\text { (genus) }\end{array}$} & \multirow{2}{*}{ Cell line } & \multirow{2}{*}{ Compound } & \multicolumn{2}{|c|}{ Neutral Red Assay } & \multirow{2}{*}{$\begin{array}{c}\text { Virus Yield } \\
\text { Reduction Assay } \\
\mathrm{EC}_{90}(\mu \mathrm{M})\end{array}$} & \multirow{2}{*}{$\begin{array}{l}\text { Selectivity } \\
\text { Index } \\
\left(\mathrm{CC}_{50} / \mathrm{EC}_{90}\right)\end{array}$} \\
\hline & & & $E C_{50}(\mu \mathrm{M})$ & $\mathrm{CC}_{50}(\mu \mathrm{M})$ & & \\
\hline \multirow{2}{*}{$\begin{array}{l}\text { HCoV-229E } \\
\text { (alpha) }\end{array}$} & BHK-21 & $\begin{array}{c}\text { AT-511 } \\
\text { sofosbuvir }\end{array}$ & $\begin{array}{r}3.3^{\mathrm{a}, \mathrm{b}} \\
>100^{\mathrm{b}}\end{array}$ & $\begin{array}{l}>100^{b} \\
>100^{b}\end{array}$ & & $\begin{array}{l}>30 \\
N / A\end{array}$ \\
\hline & Huh-7 & $\begin{array}{c}\text { AT-511 } \\
\text { chloroquine } \\
\text { hydroxychloroquine }\end{array}$ & $\begin{array}{c}1.7 / 1.6 \\
8.1 \\
7.4\end{array}$ & $\begin{array}{c}>86 \\
21 \\
26\end{array}$ & $\begin{array}{c}1.0 \\
<0.050 \\
<0.048\end{array}$ & $\begin{array}{l}>86 \\
2.6^{c} \\
3.5^{c}\end{array}$ \\
\hline \multirow{2}{*}{$\begin{array}{c}\text { HCoV-OC43 } \\
\text { (beta) }\end{array}$} & Huh-7 & AT-511 & $N D^{d}$ & $>86$ & $0.5 /<0.03$ & $>170 />3100$ \\
\hline & $\mathrm{RD}$ & AT-511 & 2.8 & $>86$ & 2.2 & $>39$ \\
\hline $\begin{array}{c}\text { MERS-CoV } \\
\text { (beta) }\end{array}$ & Huh-7 & AT-511 & $15 / 36$ & $>86$ & $17 / 56$ & $>5 />1.5$ \\
\hline $\begin{array}{c}\text { SARS-CoV } \\
\text { (beta) }\end{array}$ & Huh-7 & AT-511 & ND & $>86$ & 0.34 & $>250$ \\
\hline $\begin{array}{l}\text { SARS-CoV-2 } \\
\text { (beta) }\end{array}$ & HAE & $\begin{array}{c}\text { AT-511 } \\
\mathrm{N}^{4} \text {-hydroxycytidine }\end{array}$ & ND & $\begin{array}{c}>86^{\mathrm{e}} />8.6^{\mathrm{e}} \\
>19^{\mathrm{e}}\end{array}$ & $\begin{array}{c}0.64^{f} / 0.47^{g} \\
3.9^{h}\end{array}$ & $\begin{array}{c}>130 />18 \\
>4.8\end{array}$ \\
\hline
\end{tabular}

${ }^{\mathrm{a}} \mathrm{EC}_{90}$ (average of 2 experiments)

${ }^{\text {b}}$ Determined by MTT cell viability test

${ }^{c} C_{50} / \mathrm{EC}_{50}$ (virus yield reduction assay overestimates antiviral potency of cytotoxic compounds)

${ }^{\mathrm{d}}$ Not determined (no cytopathic effect with this virus in this cell line)

${ }^{e}$ Cytotoxicity assessed by visual inspection of cell monolayers

${ }^{\mathrm{f}}$ Average of two replicates $(0.57$ and $0.70 \mu \mathrm{M})$

${ }^{g}$ Average of two replicates $(0.52$ and $0.42 \mu \mathrm{M})$

hAverage of two replicates $(4.7$ and $3.1 \mu \mathrm{M})$

BHK-21, baby hamster kidney cell line

Huh-7, human hepatocyte carcinoma cell line (established ability to form triphosphate from AT-511)

$\mathrm{RD}$, human rhabdomyosarcoma cell line (unknown ability to form triphosphate from AT-511)

$\mathrm{HAE}$, normal human airway epithelial cell preparation (established ability to form triphosphate from AT-511)

\section{MATERIALS AND METHODS}

Cells, viruses and compounds. BHK-21 (baby hamster kidney) cells, Huh-7 (human hepatocarcinoma) cells, RD (human rhabdomyosarcoma) cells and the seasonal human coronaviruses (HCoV-229E and HCoV-OC43) were obtained from American Type Culture Collection, Manassas, VA. MERS-CoV (EMC), SARS-CoV (Urbani) and SARS-CoV-2 (USAWA1/2020) were supplied by The Centers for Disease Control and Prevention, Atlanta, GA. The HAE cell preparations (EpiAirway ${ }^{T M}$ AIR-100 or AIR-112) were purchased from MatTek 
Corporation, Ashland, MA. AT-511 and N4-hydroxycytidine were prepared for Atea Pharmaceuticals by Topharman Shanghai Co., Ltd., Shanghai, China and Oxeltis, Montpellier, France, respectively. Chloroquine and hydroxychloroquine were purchased from Mason-Chem, Palo Alto, CA and sofosbuvir was purchased from Pharma Sys, Inc., Cary, NC.

Antiviral assays in BHK-21 cells: Test compounds were dissolved in DMSO at $100 \mathrm{mM}$ and then diluted in Minimum Essential Medium with Earle's salts (MEM-E) containing $1 \mathrm{mM}$ sodium pyruvate and $25 \mu \mathrm{g} / \mathrm{mL}$ kanamycin, supplemented with 10\% FBS (growth medium) to final concentrations of 100, 20, 4 and $0.8 \mu \mathrm{M}$ (two 24-well replica plates each). After BHK-21 cells were grown to confluency in 96-well plates, growth medium was replaced with fresh maintenance medium (growth medium with $1 \%$ inactivated FBS in place of $10 \%$ FBS) containing serially diluted test compound and HCoV-229E at a multiplicity of infection (MOI) of 0.01 . Uninfected cells in the presence of serially diluted compound were used to assess the cytotoxicity of compounds. After a 3-day incubation at $37^{\circ} \mathrm{C}$ in a humidified $5 \% \mathrm{CO}_{2}$ atmosphere, cell viability was determined by the MTT method (Pauwels et al., 1988). The effective concentration of test compound required to prevent virus-induced cytopathic effect (CPE) by $50 \%$ ( $\left.\mathrm{EC}_{50}\right)$ and to cause $50 \%$ cell death in the absence of virus $\left(\mathrm{CC}_{50}\right)$ were calculated by regression analysis.

Antiviral assays in Huh-7 and RD cells: The antiviral activities of test compounds were evaluated against human coronaviruses alpha (229E), beta (OC43), MERS (EMC) and SARS (Urbani) using a neutral red assay to determine inhibition of virus-induced and compoundinduced CPE and using a virus yield reduction (VYR) assay as a second, independent determination of the inhibition of viral replication.

Neutral red assay: Test compounds were dissolved in DMSO at a concentration of $10 \mathrm{mg} / \mathrm{mL}$ and serially diluted using eight half-log dilutions in test medium (Minimum Essential Medium supplemented with $5 \% \mathrm{FBS}$ and $50 \mu \mathrm{g} / \mathrm{mL}$ gentamicin) so that the highest test concentration was $50 \mu \mathrm{g} / \mathrm{mL}$. Each dilution was added to 5 wells of a 96 -well plate with $80-100 \%$ confluent Huh-7 or RD cells (OC43 only). Three wells of each dilution were infected with virus, and two wells remained uninfected as toxicity controls. Six untreated wells were infected as virus controls and six untreated wells were left uninfected to use as virus controls. Viruses were diluted to achieve MOIs of $0.003,0.002,0.001$ and 0.03 CCID $_{50}$ per cell for $229 \mathrm{E}, \mathrm{OC} 43, \mathrm{MERS}$ and SARS, respectively. Plates were incubated at $37 \pm 2^{\circ} \mathrm{C}$ in a humidified atmosphere containing $5 \% \mathrm{CO}_{2}$.

On day 5 (229E and OC43) or day 7 (MERS and SARS) post-infection, when untreated virus control wells reached maximum CPE, the plates were stained with neutral red dye for approximately 2 hours ( \pm 15 minutes). Supernatant dye was removed, wells were rinsed with PBS, and the incorporated dye was extracted in 50:50 Sorensen citrate buffer/ethanol for $>30$ minutes and the optical density was read on a spectrophotometer at $540 \mathrm{~nm}$. Optical densities were converted to percent of controls and the concentrations of test compound required to prevent virus-induced $\mathrm{CPE}$ by $50 \%\left(\mathrm{EC}_{50}\right)$ and to cause $50 \%$ cell death in the absence of virus $\left(\mathrm{CC}_{50}\right)$ were calculated. 
Virus yield reduction assay: Vero 76 cells were seeded in 96-well plates and grown overnight $\left(37^{\circ} \mathrm{C}\right)$ to confluence. A sample of the supernatant fluid from each compound concentration was collected on day 3 post infection ( 3 wells pooled) and tested for virus titer using a standard endpoint dilution $\mathrm{CCID}_{50}$ assay and titer calculations using the Reed-Muench equation (1938) and the concentration of compound required to reduce virus yield by $90 \%$ (EC90) was determined by regression analysis.

Antiviral assays in HAE cell preparations: The antiviral activities of test compounds were evaluated against SARS-CoV-2 (USA-WA1/2020) using made to order differentiated normal human bronchial epithelial (HAE) cells.

Cell Culture: HAE cells were grown on $6 \mathrm{~mm}$ mesh disks and arrived in kits with either 12- or 24well transwell inserts. During transportation the tissues were stabilized on a sheet of agarose, which was removed upon receipt. One insert was estimated to consist of approximately $1.2 \mathrm{x}$ $10^{6}$ cells. Kits of cell inserts (EpiAirway ${ }^{\mathrm{TM}}$ AIR-100 or AIR-112) originated from a single donor, \# 9831, a 23-year old, healthy, non-smoking, Caucasian male. The cells form polarized monolayers, the apical side of which is exposed to air and creates a mucin layer. Upon arrival, the cell transwell inserts were immediately transferred to individual wells of a 6 -well plate according to the manufacturer's instructions, and $1 \mathrm{~mL}$ of MatTek's proprietary culture medium (AIR-100-MM) was added to the basolateral side, whereas the apical side was exposed to a humidified $5 \% \mathrm{CO}_{2}$ environment. Cells were cultured at $37^{\circ} \mathrm{C}$ in a humidified atmosphere containing $5 \% \mathrm{CO}_{2}$ for one day before the start of the experiment. After the 24-h equilibration period, the mucin layer, secreted from the apical side of the cells, was removed by washing with $400 \mu \mathrm{L}$ pre-warmed $30 \mathrm{mM}$ HEPES buffered saline solution $3 \mathrm{X}$. Culture medium was replenished following the wash steps.

Viruses: Virus was diluted in AIR-100-MM medium before infection to yield a MOI when added to cultures of approximately $0.0015 \mathrm{CCID}_{50}$ per cell.

Experimental design: Each compound treatment $(120 \mu \mathrm{L})$ and virus $(120 \mu \mathrm{L})$ was applied to the apical side, and the compound treatment $(1 \mathrm{~mL})$ was applied to the basal side. As a virus control, some of the cells were treated with cell culture medium only. After a 2-h infection incubation, the apical medium was removed, and the basal medium was replaced with fresh compound or medium $(1 \mathrm{~mL})$. The cells were maintained at the air-liquid interface. On day 5 , cytotoxicity ( $\mathrm{CC}_{50}$ values) in the uninfected, compound-treated inserts was estimated by visual inspection, and the basal medium was removed from all inserts and discarded. Virus released into the apical compartment of the HAE cells was harvested by the addition of $400 \mu \mathrm{L}$ of culture medium that was pre-warmed at $37^{\circ} \mathrm{C}$. The contents were incubated for $30 \mathrm{~min}$, mixed well, collected, thoroughly vortexed and plated on Vero 76 cells for VYR titration. Separate wells were used for virus control and duplicate wells were used for untreated cell controls. Virus titers from each treated culture were determined as described above. 


\section{REFERENCES}

Beigel, J.H., Tomashek, K.M., Dodd, L.E., Meta, A.K., Zingman, B.S., Kalil, A.C., Hohmann, E., Chu, H.Y., Luetkemeyer, A., Kline, S. et al. (2020). Remdesivir for the treatment of COVID-19 - Preliminary report. N. Engl. J. Med. Jul 10, 383.

Berliba, E., Bogus, M., Vanhoutte, F., Berghmans, P.-J., Good, S.S., Moussa, A., Pietropaolo, K., Murphy, R.L., Zhou, X.-J. and Sommadossi, J.-P. (2019). Safety, pharmacokinetics, and antiviral activity of AT-527, a novel purine nucleotide prodrug, in hepatitis $C$ virus-infected subjects with or without cirrhosis.

Antimicrob. Agents Chemother. 63, e011201-19.

Eastman, R.T., Roth, J.S., Brimacombe, K.R., Simeonov, A., Shen, M., Patnaik, S. and Hall, M.D. (2020). Remdesivir: A review of its discovery and development leading to emergency use authorization for treatment of COVID-19. ACS Cent. Sci. 6, 672-683.

Ferron, F., Subissi, L., Silveira De Morais, A.T., Tuyet Le, N.T., Sevajol, M., GLuais, L., Decroly, E., Vonrhein, C., Bricogne, G., Canard, B., et al. (2018). Structural and molecular basis of mismatch correction and ribavirin excision from coronavirus RNA. Proc. Natl. Acad. Sci. USA 115, E162-E171.

Good, S.S., Moussa, A., Zhou, X.-J., Pietropaolo, K. and Sommadossi, J.-P. (2020). Preclinical evaluation of AT-527, a novel guanosine nucleotide prodrug with potent, pan-genotypic activity against hepatitis $C$ virus. PLoS ONE 15, e0227104.

Jonsdottir, H.R. and Dijkman, R. (2016). Coronaviruses and the human airway: a universal system for virus-host interaction studies. Virol. J. 13, 1-9.

Mason, R.J. (2020). Pathogenesis of COVID-19 from a cell biology perspective. Eur. Respir. J. 55 April 9, 200067.

Mungar, O., Berliba, E., Bourgeois, S., Cardona, M., Jucov, A., Good, S.S., Moussa, A., Pietropaolo, K., Zhou, X.-J., Brown, N.A., and Sommadossi, J.-P. (2020). A combination of AT-527, a potent pan-genotypic guanosine nucleotide prodrug, and daclatasavir was well-tolerated and effective in HCV-infected subjects. EASL International Liver Congress, August 27-29, www.ilc-congress.eu, abstract THU438.

Pauwels, R., Balzarini, J., Baba, M., Snoeck, R., Schols, D., Herdewijn, P., Desmyter, J. and De Clercq, E. (1988). Rapid and automated tetrazolium-based colorimetric assay for the detection of anti-HIV compounds. J. Virol. Methods 20, 309-321.

Reed, $L$ and Muench, H. (1938). A simple method for estimating fifty percent endpoints. Am. J. Hygiene 27, 493-497.

Sheahan, T.P., Sims, A., Zhou, S., Graham, R.T., Pruijssers, A.J., Agostini, M.L., Leist, S.R., Schafer, A., Dinnon, K.H., III, Stevens, L.J. et al. (2020). Sci. Transl. Med. 12, 541.

Subissi, L., Posthuma, C.C., Collet, A., Zevenhoven-Dobbe, J.C., Gorbalenya, A.E., Decorly, E. Snijder, E.J., Canard, B. and Imbert, I. (2014). One severe acute respiratory syndrome coronavirus protein complex integrates processive RNA polymerase and exonuclease activities. Proc. Natl. Acad. Sci. USA. 111, E3900E3009.

Wang, M., Cao, R., Zhang, L., Yang, X., Liu, J., Xu, M., Shi, Z., Hu, Z., Zhong, W. and Xiao, G. (2020). Remdesivir and chloroquine effectively inhibit the recently emerged novel coronavirus (2019-nCoV) in vitro. Cell Research. 30, 269-271. 